\title{
Psychosomatic Medicine
}

National Cancer Institute

\section{Source}

National Cancer Institute. Psychosomatic Medicine. NCI Thesaurus. Code C17038.

A branch of medicine concerned with the relationship between emotion and body function. 